* Doutora em Direito pela Universidad de Barcelona (UB-Espanha) Docente da Universidade Estadual Julio de Mesquita Filho (UNESP). Professora das disciplinas juridicas do curso de Administração Pública da Faculdade de Ciências e Letras de Araraquara (FCL-UNESP). Docente do Programa de Pós Graduação em Direito da UNESP-FRANCA. pmarchetto@fclar.unesp.br

** Faculdade Autônoma de Direito - FADISP. Doutoranda pela FADISP: Função Social do Direito Constitucional, na linha de pesquisa Constitucionalização dos Institutos do Direito Privado É graduada em Direito pelo Centro Universitário de Araraquara (1994), especialização em Direito Civil e Processual Civil, pelo Centro Universitário de Araraquara/INPG (1999), Mestrado em Direito pela Universidade Paulista $\left(\begin{array}{lllll}2 & 0 & 0 & 4\end{array}\right)$. adriana.telles@superig.com.br

\section{Considerações da lei falimentar no direito brasileiro em comparação ao direito francês}

\author{
BANKRUPTCY LAW CONSIDERATIONS IN \\ BRAZILIAN LAW COMPARED TO FRENCH LAW
}

Patricia Borba Marchetto*

Adriana Augusta Telles de Miranda**

Resumo: O presente artigo traz breve comparação do Direito Falimentar brasileiro entre o Direito Francês das sociedades em dificuldades. Dessa forma, uma análise dos dispositivos legais dos dois países, para ao final averiguar se ambos visam à preservação da empresa, respectivamente, Lei de Recuperação e Falência - Lei n. ${ }^{\circ}$ 11.101/05, em Code de Commerce - Código Comercial Francês, capítulo Des difficultés des entreprises.

Palavras-chaves: Falência - Recuperação Judicial - Direito Comparado.

Abstract: This article brings brief comparison of Brazilian bankruptcy law between the French law of societies in difficulties. In this way, an analysis of the legal provisions of the two countries, to the end see if both aim at the preservation of the company, respectively, Law Recovery and Bankruptcy no. 11.101/05, in Code de Commerce-French commercial code, chapter Des difficultés des enterprises.

Keywords: Bankruptcy - Judicial Recovery- Comparative Law. 


\section{INTRODUÇÃO}

O mercado empresarial está fortemente alicerçado nas múltiplas relações jurídicas envolvendo a solvabilidade dos créditos, numa relação obrigacional entre credores e devedores.

O adimplemento da prestação pelo devedor é a presunção mais almejada pelo credor, presunção esta que se exaure na insolvência do devedor. Numa relação simples, o não pagamento permite ao credor exigir do devedor o cumprimento da prestação, incluindo juros e correção monetária, recaindo a dívida na constrição do patrimônio do devedor, tratando-se de credor quirografário.

Já para as empresas, considerando suas especificidades e a dimensão das relações jurídicas que são geradas pelas atividades exercidas, mormente a possibilidade de se encontrar em estado de insolvência ou em crise econômica financeira, necessária a Lei de Falência e Recuperação de Empresas, Lei n. ${ }^{\circ}$ $11.101 / 2005$ (LRF), que de forma simplista passa a discorrer.

Por outro lado, a relação comercial se entrelaça em empresas internacionais, numa forma de internacionalização da atividade econômica. Não se pretende a priori, um estudo profundo sobre falência transfronteiriça, tão somente uma comparação do direito falimentar entre os países Brasil e França - no direito Francês -Des difficultés des entreprises ${ }^{l}$.

A Lei de Falência brasileira encontra-se dividida em 8 (oito) capítulos, tratando de disposições preliminares; disposições comuns à recuperação judicial e à falência; da recuperação judicial; da convolação da recuperação judicial em falência; da falência; da recuperação extrajudicial; das disposições penais e por fim, das disposições finais transitórias.

De forma sistemática, e inserida no Código Comercial Francês, o livro VI disciplina regras sobre as dificuldades das empresas, assim denominada: Des difficultés des entreprises; TITRE Ier : De la prévention des difficultés des entreprises (Procedimento de prevenção nas dificuldades das empresas); TITRE II : De la sauvegarde (Procedimento de recuperação judicial); TITRE III : Du redressement judiciaire (Procedimento com intervenção judicial); TITRE IV : De la liquidation judiciaire (Liquidação judicial); TITRE V : Des responsabilités et des sanctions (responsabilidades e sanções); TITRE VI : Des dispositions générales de procédure (Disposições processuais gerais);

\footnotetext{
Das dificuldade das empresas.
}

SCIENTIAIURIS, Londrina, v.18,n.1,p.45-59,jul.2014 | DOI: 10.5433/2178-8189.2014v18n1p45 
TITRE VII : Dispositions dérogatoires particulières aux départements de la Moselle, du Bas-Rhin et du Haut-Rhin (Legislação com procedimento específico para de competência territorial para Lorena, Bas-Rhin e Haut Rhin).

\section{A LEI DE FALÊNCIA NO DIREITO BRASILEIRO}

A Lei n. ${ }^{\circ}$ 11.101/2005 - Lei de Falência e Recuperação de Empresas reconhece o valor social que a empresa representa no mundo atual e orienta pela sua preservação. Nesse sentido comenta Manoel Justino Bezerra Filho (2005, p. 43):

... poder-se-ia definir como centralizada na preocupação de possibilitar a recuperação da sociedade empresária, de tal forma que, havendo sinais de que determinada empresa não estaria caminhando da melhor forma, propiciasse a Lei um modo de intervenção que, logo aos primeiros sinais da crise, aplicasse remédios que pudessem evitar o agravamento da situação. Dessa forma, seria possível tentar sanear sua situação econômica, preservando-se a empresa como organismo vivo, com o que se preservaria a produção, mantendo-se os empregos e, com o giro empresarial voltado à normalidade, propiciando-se o pagamento de todos os credores.

Para a melhor interpretação da norma divide-se o tema em processo falimentar, e recuperação judicial e recuperação extrajudicial.

\subsection{Do processo falimentar}

A falência é aplicada somente ao empresário individual ou a sociedade empresária, isto é, não se aplica as sociedades simples, que tem sua regulamentação no instituto insolvência civil fundamentado pelo art. 748 e seguintes do Código de Processo Civil.

Possui legitimidade ativa para ingressar com o pedido de falência, nos termos do artigo 105 da LRF o próprio empresário individual ou a sociedade empresária, desde que a pessoa jurídica encontre-se devidamente registrada na junta comercial, conforme dispõe o artigo 97 da referida lei. Trata-se nesta hipótese do pedido de autofalência. Também, pode pleitear a falência, qualquer credor, pessoa física ou pessoa jurídica, devidamente constituída e regularizada. 
A legitimidade nos termos do artigo $2^{\circ}$ da Lei Falimentar é representada pelo empresário individual ou a sociedade empresária, exceto as empresas públicas; as sociedades de economia mista; as operadoras de plano de saúde; as cooperativas de créditos; as instituições financeiras públicas ou privadas, e as seguradoras.

Para o procedimento de a falência cabe observar três (03) espécies de créditos que permitam o requerimento, como dispõe o artigo 94 da LRF.

A primeira denominada impontualidade injustificada, isto é, a falta de pagamento de obrigação líquida sem justificativa, referente a título executivo judicial ou extrajudicial acima de 40 salários mínimos. Cabe observar que os referidos títulos devem ser protestados.

A segunda espécie de crédito consiste na execução frustrada, pela falta de pagamento ou de nomeação de bens passíveis de penhora, em processo de execução, na tríplice omissão: não pagou; não depositou em juízo, nem nomeou bem a penhora. Ajuíza-se ação a partir da extração de cópia do processo de execução.

A terceira, denominada de atos de falência, dada a liquidação precipitada por parte do empresário em desaparecer aos poucos com os bens, na hipótese de fraude contra credores, simulação de venda e transferência de bens, e abandono do estabelecimento.

Cumprido os pressupostos e ajuizada a ação, citado o devedor, ele poderá, nos termos do art. 98 da LRF contestar a ação no prazo de 10 dias; ou, fazer o depósito elisivo, que corresponde ao pagamento do valor principal, acrescido de juros e correção monetária, mais honorários advocatícios, porém, cabível na hipótese da inicial fundamentada na impontualidade injustificada e na execução frustrada. Nesta hipótese não se decreta a falência. Ou, ainda, o devedor pode pedir a recuperação judicial nos termos do artigo 75 da LRF.

O julgamento do processo de falência permite uma sentença declaratória de falência, que se dá com a quebra da sociedade. Ou então, uma sentença denegatória, improcedente. Cabe recurso nos termos do artigo 100 da LRF, respectivamente, agravo de instrumento para a declaratória e o recurso de apelação para a sentença denegatória.

Uma vez proferida a sentença declaratória, o juiz nomeará um administrador judicial, que poderá ser um advogado, economista, administrador de empresa, contador, ou também, uma pessoa jurídica, desde que representada por um profissional responsável, e identificado pessoalmente (art. 21 da LRF). 
O administrador desenvolverá seu trabalho sob a fiscalização do juiz e do Comitê de Credores, qual seja: providenciar a arrecadação dos bens que se encontram na posse da falida; avaliá-los e posterior, vendê-los. Com a venda judicial dos bens, que pode ocorrer na forma de leilão, o pregão e a venda por proposta fechada, ter-se-á a realização do ativo.

O produto com a venda dos bens volta para a massa falida dando ensejo ao pagamento de todos os credores e não somente daquele que ajuizou a ação. Para tanto, o legislador, no artigo 83 da LRF exibe a ordem de classificação dos créditos.

De acordo com a classificação dos créditos, o primeiro pagamento a ser realizado é o crédito trabalhista até 150 salários mínimos por credor, acima desse valor, o crédito corresponde a quirografário e ainda, sem limite os decorrentes de acidente de trabalho. Na sequência tem-se: crédito com garantia real, até o valor do bem dado em hipoteca, penhor ou anticrese, sendo que o valor excedente torna-se crédito quirografário; os créditos tributários, excetos as multas tributárias; os créditos com privilégio especial; os créditos com privilégio geral; os créditos quirografários, representados pelos contratos em geral e títulos de créditos, bem como os excedentes dos créditos trabalhistas e com garantia real; as multas, inclusive as tributárias, denominadas pela doutrina de subquirografária e por último, o crédito subordinado, aqueles pertencentes aos sócios da empresa falida (sócio credor da empresa).

Entretanto, cabe ressalva, que antecede ao pagamento da relação dos credores outras categorias: em primeiro lugar tem-se o credor proprietário com direito de preferência absoluta, nessa hipótese não ocorre à habilitação de crédito na falência, mas pedido de restituição de bem nos termos do art. 85 LRF. Em segundo lugar o credor extraconcursal, aquele oriundo de valores pagos ou gastos após a decretação da falência ou da recuperação judicial, consoante art. 84 e 67 da LRF. Em terceiro lugar, o credor concursal, já mencionado alhures (art. 83 da LRF), os quais serão relacionados pelo devedor quando da decretação da falência, pelo prazo de 5 dias.

Após o pagamento dos credores cabe a prestação de contas pelo administrador, e encerra-se o processo falimentar, nos termos do artigo 156 LRF. Observe-se que o empresário com falência decretada ficará inabilitado de exercer atividade empresarial.

O período da inaptidão fica adstrito a sentença de extinção das obrigações do falido, que conforme o art. 158 LRF têm como requisitos: o pagamento de todos os credores; ou pagamento de $50 \%$ dos créditos quirografários; ou decurso 
do prazo de 10 anos se condenado em crime falimentar, contados do encerramento da falência; ou 5 anos, contados do encerramento da falência, na ausência de condenação, com pedido de extinção das obrigações do falido para o juízo. Após o cumprimento de qualquer requisito e com a sentença, permitese exercer atividade empresarial.

\subsection{Da recuperação judicial}

A recuperação judicial pode ser ajuizada pelo empresário individual ou as sociedades empresárias, que se encontra em crise econômica financeira, cuja prova se faz representada pelos (3) três últimos demonstrativos contábeis do exercício social (art. 51 LRF), podem ajuizar ação pleiteando a recuperação judicial.

Possui legitimidade ativa para se ingressar com ação de recuperação judicial, além do empresário individual ou as sociedades empresárias, por força do parágrafo único do art. 49 LRF, o cônjuge sobrevivente, o herdeiro do devedor, o inventariante e o sócio remanescente.

Para se ingressar com a ação de recuperação judicial, dispõe o artigo 48 da LRF os requisitos necessários, ou seja, somente pode pleitear o devedor que exerça atividade regular há mais de 2 anos, e cumulativamente, não esteja falido, não tenha obtido concessão de recuperação há menos de 5 anos (ou 8 anos se for microempresa ou EPP) e, não tenha sido condenado por crime falimentar.

Todos os créditos até a data do pedido da recuperação sejam vencidos sejam vincendos, podem integrar o plano de recuperação, com a ressalva dos créditos financeiros, isto é, com garantia fiduciária, arrendamento ou reserva de domínio ( $\$ 3^{\circ}$ do art. $49 \mathrm{LRF}$ ).

O juiz ao receber a ação com a comprovação da crise econômica financeira concederá o despacho de processamento, nomeando o administrador e suspendendo todas as ações de execução. Com a publicação do despacho, inicia-se a contagem do prazo de 60 dias para que o devedor, a seu critério, apresente o plano de recuperação judicial. O plano poderá conter forma de parcelamento da dívida, transferência do controle societário para o credor, fusão de empresas para diminuir gastos etc., rol ilustrativo disposto no art. 50 da LRF.

Com a exibição do plano de recuperação judicial pelo devedor, dá-se acesso aos credores, os quais poderão concordar ou apresentar objeção 
no prazo de 30 dias, consoante art. 56 da LRF. Na concordância haverá a recuperação. Na hipótese de discordância dos credores, o juiz convocará uma assembleia geral dos credores, que poderá aprovar o plano, bem como alterá-lo, ou então, reprovar o plano ensejando a convolação da falência $\left(\S 4^{\circ}\right.$ art. 56).

Como se vê, a assembleia geral somente será convocada se houver objeções ao plano apresentado, o administrador presidirá os trabalhos, e lavrará ata com todas as votações e discussões, com a participação dos credores, devedor, devendo ser entregue ao juiz em 48 horas. Cabe ressaltar que qualquer pessoa pode assistir a assembléia, salvo se houver segredo de justiça decretado.

A deliberação sobre o plano de recuperação deverá observar os seguintes princípios:

- universalidade, todas as três classes de credores sujeitas ao plano deve ser ouvida;

- voto exclusivamente por cabeça - na classe I (créditos do trabalho e acidente de trabalho) a proposta deverá ser aprovada por maioria simples;

- voto por dupla maioria, nas classes II e III (credores quirografários e com garantia real), a proposta deve ser aprovada por credores que represente, mais da metade do valor total dos créditos presentes à assembleia e, cumulativamente, pela maioria simples dos credores presentes. ,

A falência é conseqüência legal da rejeição, com uma única exceção, o juiz poderá conceder a recuperação judicial com base num plano rejeitado, nos termos do artigo $58, \S \S 1^{\circ}$ e $2^{\circ}$ se de forma cumulativa e na mesma assembléia, que o voto favorável de credores que representem mais da metade do valor de todos os créditos presentes à assembléia, independentemente de classes; a aprovação de 2 (duas) das classes de credores ou, caso haja somente 2 (duas) classes com credores votantes, a aprovação de pelo menos 1 (uma) delas; e, na classe que o houver rejeitado, o voto favorável de mais de $1 / 3$ (um terço) dos credores, computados por cabeça e voto por dupla maioria. A recuperação judicial será concedida se o plano não implicar tratamento diferenciado entre os credores da classe.

O quorum especial de aprovação pode ser aferido em qualquer das votações preliminares ou finais, daí a importância de todas as votações havidas na assembléia estarem devidamente registradas na ata. Porém a recuperação não é um beneficio titularizado e concedido pelo estado, como 
ocorria na concordata, é um acordo coletivo, uma transação judicial coletiva com os credores, por isso trata-se de uma exceção.

Observa-se que inexiste prazo para a recuperação judicial, o lapso temporal fica adstrito ao período programado no plano de recuperação. Entretanto, o prazo de 2 (dois) anos descrito no art. 61 da LRF refere-se ao período em que o devedor permanecerá em recuperação judicial acompanhada pelo juiz, ou seja, tratando-se de plano superior aos dois anos, mantêm-se o cumprimento por parte do devedor, na conjectura de inadimplemento, cabe execução pelo credor.

\subsubsection{Recuperação Judicial Especial}

No direito falimentar brasileiro há possibilidade de as microempresas e as empresas de pequeno porte (EPP) pleitear a recuperação judicial comum, já exibida acima, ou então, pleitear a recuperação judicial especial.

A recuperação judicial especial abrange exclusivamente os créditos quirografários e o plano de recuperação se encontra definido no art. 71 da LRF; previsão de parcelamento em até 36 parcelas iguais e sucessivas, acrescidas de correção monetária e juros de $12 \%$ ao ano, com vencimento da primeira parcela em até 180 dias contado da distribuição do pedido de recuperação. Nesta hipótese não faculta ao devedor apresentar plano de recuperação.

Preleciona Ricardo Negrão $(2011,276)$ a diferença entre os planos de recuperação judicial especial e o ordinário:

a) a legitimidade ativa para o plano especial, destinados aos microempresários e empresários de pequeno porte; b) a extensão do universo de credores abrangidos; c) a simplificação do procedimento; e d) a possibilidade de adoção de um único meio de recuperação, dilação do prazo para pagamento dos credores.

\subsection{Recuperação extrajudicial}

Consiste na negociação do devedor com os próprios credores dos créditos, cujo rol se encontram exibidos na classificação de créditos, mas com a ressalva dos créditos trabalhistas e tributários que estão excluídos da recuperação extrajudicial. 
Gladston Mamede (2006, p. 301) recomenda a distinção de nomenclatura em recuperação extrajudicial ordinária e a recuperação extrajudicial extraordinária. Ordinária, a prevista nos arts. 161 e 162 da LRF que traduz a adesão voluntária de todos os credores, ou seja, o devedor apresenta plano de recuperação para todos os credores das dívidas vencidas, com a concordância de todos, homologa-se judicialmente transformando em título executivo judicial.

Na recuperação extrajudicial extraordinária, fundamentada no art. 163 da LRF, o devedor requererá a homologação do plano de recuperação com adesão apenas de $3 / 5$ dos credores de uma mesma espécie, vinculando a minoria não aderente.

Explica Vera Helena de Mello Franco (2008, p. 257):

Na primeira a hipótese a homologação judicial não é obrigatória; já na segunda é essencial para que atinja a todos os credores. Note-se que a maioria necessária para que o plano seja aprovado é de 3/5 (três quintos) de todos os créditos de cada espécie atingida e não, simplesmente, dos créditos habilitados, independente da espécie de cada um.

\section{A LEI DE FALÊNCIA NO DIREITO FRANCÊS}

Inicia-se a análise da legislação francesa observando que a aplicabilidade da regra de falência se estende tanto para pessoa física como para pessoa jurídica, além do consumidor endividado, diferentemente do direito brasileiro. Entretanto, manter a empresa atuando, também é orientação no Direito Francês. José Cretella Neto (2012, p. 13) descreve:

Hoje, na França, como na maioria dos países industrializados, a legislação inspira posicionamento diferente do Poder Público (isto é, medidas não mais apenas punitivas, como no passado), os quais, por intermédio da atuação dos Comitês de Reestruturação, promovem a adequação da sociedade em dificuldades, utilizando métodos modernos de Administração de Empresas, com o concurso de executivos qualificados, que tudo fazem para manter a empresa "viva".

A legislação regulamenta ainda, as demissões e, no intuito de minimizar desemprego apresenta plano de compensação e retreinamento de funcionários (CRETELLA NETO, 2012, P. 14). 


\subsection{Do procedimento de prevenção para as empresas em dificuldade financeira (TITRE Ier : De la prévention des difficultés des entreprises).}

Esse procedimento destina reorganizar a empresa permitindo o exercício de suas atividades econômicas, seja na mantença do quadro de empregados seja na liquidação do passivo.

Trata-se de uma conciliação amigável e confidencial, onde os credores são notificados (artigo L611-7 do Code de Commerce ${ }^{2}$ ) dando-se início ao processo de conciliação. É um processo coletivo em que o devedor tem a grande vantagem de negociar com seus credores por meio de um plano de recuperação, para tanto, a empresa não pode se encontrar em estado de insolvência por mais de 45 dias (artigo L611-4 do Code de Commerce).

Nesse procedimento de prevenção permite-se que os funcionários da empresa informem ao juiz as dificuldades enfrentadas pelo devedor, facilitando a recuperação antes que ocorra a insolvência.

O juiz presidente nomeia um conciliador "ad hoc" que negociará o pagamento escalonado das dívidas com os principais credores, os únicos cientes das dificuldades do devedor. O devedor também pode nomear mandatário "ad hoc".

Com o início da conciliação, isto é, o acordo entre credores e devedor, suspende provisoriamente as execuções. Porém, considerando que o procedimento é confidencial, não atinge os credores que não aderiram ao plano consoante artigo L611-10-1 do Code de Commerce.

O conciliador é nomeado por um período não superior a quatro meses, podendo ser prorrogado o prazo desde que se apresente fundamentação ao juiz.

Havendo interesse pessoal direto ou indireto no processo; relação direta ou indireta, de qualquer natureza, entre conciliador e um credor; motivos de desconfiança; ou se o conciliador já tiver sido permanentemente cancelado ou removido de sua função, o devedor pode impugnar a nomeação do conciliador no prazo de 15 dias.

Com a aprovação do acordo entre credores e devedor encerra-se o processo de conciliação (artigo L611-10 do Code de Commerce) e na hipótese de desacordo, as partes podem se beneficiar da sauvegarde.

\footnotetext{
${ }^{2}$ Código Comercial
} 


\subsection{Do procedimento de recuperação (TITRE II : De la sauvegarde).}

O procedimento de sauvegarde visa facilitar a reorganização da empresa para permitir o exercício da atividade econômica e a liquidação de passivos. Favorece pessoa natural, pessoa jurídica, agrícolas e profissionais liberais com dificuldades financeiras, mas que ainda não se encontrem na condição de cessão de pagamento. Possui competência territorial, o Tribunal de Comércio em que o devedor tem a sede da sua empresa.

É condição para abertura do processo de sauvegarde que a empresa devedora, pessoa física ou profissional liberal apresente por meio de seus representantes administradores o comprovante da dificuldade financeira ou impossibilidade de pagamento de dívidas, por meio de um dossiê (artigos L 6201, R 612 -1 e R 621-1 do Code de Commerce).

$\mathrm{O}$ devedor entrega ao administrador a lista de credores, o montante das dívidas e os contratos, bem como informa sobre processos pendentes de cobrança (art. L622-6 do Code de Commerce - alterado pela Lei n ${ }^{\circ} 100$, de 28 de Janeiro de 2013).

A abertura do procedimento sauvegarde permite ao juiz da falência acompanhar e monitorar todo o processo, designando a missão do administrador, nomeando um representante dos empregados, eleito por eles; um especialista ou expert; um ou mais administradores no número de empregados e volume de negócios; um representante legal nomeado para agir em nome e para o benefício dos credores; um ou mais controladores de credores.

No procedimento há um período de observação de até seis meses para a realização de diagnóstico econômico e social da empresa, bem como um inventário dos bens do devedor, que pode excepcionalmente ser renovado por uma única vez, mediante decisão fundamentada a pedido do administrador, do devedor ou do Ministério Público (artigo L621-3 do Code de Commerce).

Para viabilizar a recuperação do devedor, permitindo a continuidade da operação da empresa seja de forma total ou parcial, elabora-se o plano de sauvegarde (artigo L626-2 do Code de Commerce), onde se projeta e se identifica as perspectivas de recuperação de acordo com as possibilidades e modalidades de atividades, condições de mercado e financiamento disponível, que será aprovado pelo Comitê dos Credores ou comissão das instituições de crédito.

Na impossibilidade do cumprimento do plano de recuperação no prazo máximo, o juiz ordena falência ou liquidação. 


\subsubsection{Da sauvegarde financeira acelerada.}

O procedimento da sauvegarde financeira acelerada é precedida de uma conciliação obrigatória, não tem efeito sobre os credores financeiros e dá origem a um plano para cumprimento no prazo máximo de dois meses.

Possui como objetivo impor rapidamente uma reestruturação financeira devido ao apoio generalizado dos credores, bem como para preservar a atividade operacional do devedor em dificuldade.

Trata-se de um procedimento limitado para empresas com mais de 150 funcionários e 20 milhões de faturamento, cujas contas certificadas por um auditor ou estabelecidas por um contador, portanto, difere da sauvegarde descrita nos artigos art. L 620-1 a 627-4 do Code de Commerce.

\subsection{Da recuperação com intervenção judicial (TITRE III: Du redressement judiciaire)}

A legislação francesa tem como regra procedimentos com intervenção do juiz e coletivos, seja na prevenção seja na recuperação, e permite a continuidade do funcionamento da empresa, a manutenção do emprego e da liquidação de passivos.

A recuperação - Du redressement judiciaire se dá de forma judicial e por meio do processo de falência (artigo L. 631-1 do Code de Commerce), em face da dificuldade do devedor em cumprir com suas responsabilidades atuais diante seus ativos disponíveis.

É requisito essencial que o pedido ocorra dentro de 45 dias da cessação dos pagamentos, a menos que o devedor tenha pedido a abertura de um processo de conciliação.

Além do devedor, possui legitimidade para ingressarem com o pedido de falência o credor; o Ministério Público, desde que não há nenhum processo de conciliação em curso; e o Tribunal se houver falha do processo de conciliação.

Igualmente, podem ser o devedor qualquer empresa comercial, artesanal, agrícola ou profissional liberal (individual ou empresarial) bem como as pessoas jurídicas de direito privado.

Para que ocorra a recuperação esse processo de falência dá origem a um plano de recuperação devidamente aprovado, não podendo exceder 10 anos de atividade, se necessária haverá a criação de dois comitês de credores (arts. L 262-29 e 262-30 do Code de Commerce). 
O plano de recuperação com a reorganização societária será oferecido pelo administrador com apoio do devedor, depois de avaliar as condições econômicas e sociais da empresa, especificando a origem, a extensão e a natureza de suas dificuldades, haja vista ser o administrador o responsável por todas as decisões de administração e conservação da empresa, embora apoiado do devedor.

O malogro plano de recuperação caracterizada pela insolvência do devedor dá ensejo à abertura do processo de insolvência judicial.

\subsection{Da liquidação judicial (TITRE IV : De la liquidation judiciaire)}

A liquidação judicial é estabelecida a qualquer devedor insolvente (artigo L 640-2 do Code de Commerce), o objetivo não é salvar a empresa, mas a distribuição dos bens do devedor entre os vários credores, tornando devido imediatamente todas as reivindicações. Assim, notadamente, será concedida a liquidação quando as dificuldades enfrentadas pela empresa são irreversíveis e nenhuma recuperação possível. Trata de solução definitiva como último recurso, devido à insolvência do devedor.

Nomeado o síndico, o devedor é retirado da administração e ocorre à disposição dos seus bens, o que significa o fim da atividade da empresa. A realização de ativos ocorre de duas formas diferentes: ou a venda total ou parcial da empresa através de um plano de venda, ou, por meio de venda isolada de vários ativos disponíveis para a empresa.

O encerramento da liquidação é estabelecido pelo juiz do Tribunal de Comércio, e pode ocorrer em duas situações distintas, ou seja, quando não há mais passivo circulante ou o liquidante está na posse de quantidades suficientes para satisfazer os credores; ou, quando os ativos forem insuficientes para operar a liquidação.

Há, ainda, a disposição legal sobre a liquidação simplificada, com prazo de encerramento de um ano. Para que ocorra, são requisitos necessários que os bens do devedor sejam vendidos em leilão publico no período de três meses após a determinação de liquidação; o devedor não possuiu mais de cinco funcionários nos últimos seis meses antes da abertura do procedimento, e, o volume dos negócios, excluindo dívida com impostos, não ultrapasse 750 mil Euros. 


\section{CONSIDERAÇÕES FINAIS}

A análise das leis brasileira e francesa exibe pontos comuns e semelhantes, mas outros, totalmente divergentes.

Nota-se que ambas visam o procedimentos de recuperação do devedor, no intuito de manter as múltiplas relações jurídicas no mercado empresarial. A relação do devedor com os credores podem ficar até mais fortalecidas, diante a possibilidade de reorganizar a empresa no plano de recuperação.

Como ponto comum e na hipótese de o devedor se tornar insolvente, a falência como quebra da atividade empresarial.

A principal divergência observada no confronto das normas está na legitimidade, ou na extensão da aplicabilidade da norma. No direito brasileiro a LRF disciplina a recuperação e a falência dos empresários individuais ou das sociedades empresárias, e, não incluem nesse rol, as empresas públicas; as sociedades de economia mista; as operadoras de plano de saúde; as cooperativas de créditos; as instituições financeiras públicas ou privadas, e as seguradoras.

O direito francês legitima a recuperação e falência a pessoa natural, a pessoa jurídica, agrícolas, profissionais liberais e consumidores.

Por fim, não se pode olvidar que do início ao fim dessa narrativa buscouse tão somente colacionar os direitos relacionados à recuperação e à falência de uma pessoa jurídica, por isso breves considerações da lei falimentar no direito brasileiro em comparação ao direito francês.

As normas são ricas em detalhes e só um estudo minucioso com foco de pesquisa aprofundado para exibir as diferenças dos direitos de forma mais incisiva, o que pode ser objeto de outro trabalho.

\section{REFERÊNCIAS}

BEZERRA FILHO, Manoel Justino. Nova lei de recuperação e falência comentada/Lei 11.101, de 9 de fevereiro de 2005, comentário artigo por artigo. 3. ed. São Paulo: Editora Revista dos Tribunais, 2005.

\section{BRASIL [Leis,] Códigos Civil; Comercial; Processo Civil;}

Constituição Federal e legislação complementar / obra coletiva de autoria da Editora Saraiva com a colaboração de Antonio Luiz de Toledo Pinto, Márcia Cristina Voz dos Santos Windt e Livia Céspedes - 7. Ed. - São Paulo: Saraiva, 2011. 
COELHO. Fábio Ulhoa. Comentários à nova lei de falência e de recuperação de empresas (Lei 11.101, de 9-2-2005). São Paulo: Saraiva, 2005.

CRETELLA NETO, José. Nova LeI de recuperação judicial e falências. 2 ed. Rio de Janeiro: GZ Ed., 2012.

DEL'OLMO, Florisval de Souza. Curso de direito internacional privado, $9^{\mathrm{a}}$ ed. Rio de Janeiro: forense, 2011.

FRANCO. Vera Helena de Mello. SZTAJN, Rachel. Falência e recuperação da empresa em crise. Rio de Janeiro: Elsevier, 2008.

FRANÇA. Código Comercial. http://www.legifrance.gouv.fr. Acessado em: 21 de abril de 2013.

. Código Comercial comentários. http://www.documentissime.fr Acessado em: 21 de abril de 2013.

MAMEDE, Gladston. Direito empresarial brasileiro: falência e recuperação de empresas, vol. 4. São Paulo: Atlas, 2006.

NEGRÃO. Ricardo. Direito empresarial: estudo unificado. $3^{a}$ Ed. Ver.. São Paulo: Saraiva, 2011.

Artigo recebido em: 30/10/2013 Aprovado para publicação em: 30/06/2014

Como citar: MARCHETTO, Patricia Borba. MIRANDA, Adriana Augusta Telles. Considerações da lei falimentar no direito brasileiro em comparação ao direito francês. Scientia Iuris, Londrina, v.18, n.1, p.45-59, jul. 2014. DOI: 10.5433/2178-8189.2014v18n1p45. 